\title{
Functional Mapping of Human Learning: A Positron Emission Tomography Activation Study of Eyeblink Conditioning
}

\author{
Teresa A. Blaxton, ${ }^{1}$ Thomas A. Zeffiro, ${ }^{2}$ John D. E. Gabrieli, ${ }^{3}$ Susan Y. Bookheimer, ${ }^{1}$ Maria C. Carrillo, ${ }^{4}$ \\ William H. Theodore, ${ }^{1}$ and John F. Disterhoft ${ }^{4}$ \\ 1 Epilepsy Research Branch, National Institute of Neurological Disorders and Stroke, Bethesda, Maryland 20892, \\ 2Laboratory of Neurosciences, National Institute of Aging, Bethesda, Maryland 20892, 3Department of Psychology, \\ Stanford University, Stanford, California 94305, and ${ }^{4}$ Department of Cell and Molecular Biology, Northwestern University, \\ Chicago, Illinois 60611
}

Regional cerebral blood flow (rCBF) was measured using positron emission tomography during eyeblink conditioning in young adults. Subjects were scanned in three experimental conditions: delay conditioning, in which binaural tones preceded air puffs to the right eye by $400 \mathrm{msec}$; pseudoconditioning, in which presentations of tone and air puff stimuli were not correlated in time; and fixation rest, which served as a baseline control. Compared with fixation, pseudoconditioning produced $\mathrm{rCBF}$ increases in frontal and temporal cortex, basal ganglia, left hippocampal formation, and pons. Learning-specific activations were observed in conditioning as compared with pseudoconditioning in bilateral frontal cortex, left thalamus, right medial hippocampal formation, left lingual gyrus, pons, and bilateral cerebellum; decreases in rCBF were observed for bilateral temporal cortex, and in the right hemisphere in puta- men, cerebellum, and the lateral aspect of hippocampal formation. Blood flow increased as the level of learning increased in the left hemisphere in caudate, hippocampal formation, fusiform gyrus, and cerebellum, and in right temporal cortex and pons. In contrast, activation in left frontal cortex decreased as learning increased. These functional imaging results implicate many of the same structures identified by previous lesion and recording studies of eyeblink conditioning in animals and humans and suggest that the same brain regions in animals and humans mediate multiple forms of associative learning that give meaning to a previously neutral stimulus.

Key words: learning; eyeblink conditioning; positron emission tomography (PET); cerebellum; hippocampus; frontal cortex; basal ganglia
No form of associative learning has been more widely investigated than Pavlovian classical conditioning. The best understood mammalian conditioning paradigm is delay eyeblink conditioning, in which a neutral conditioned stimulus (CS) such as a tone is paired with an unconditioned stimulus (US) such as an air puff to the eye. The air puff is a US in that it produces a reflex eyeblink response without any previous learning. During conditioning trials, the onset of the tone begins a short time before the delivery of the air puff, and the tone is presented continuously until it coterminates with the puff. With repeated pairings, the tone comes to elicit an eyeblink conditioned response (CR) that occurs before the puff is presented, indicating that the association between the tone and the air puff has been learned.

Eyeblink conditioning originally was used to study learning in humans and was subsequently adapted for use in the rabbit (Gormezano, 1966). Studies in rabbits and cats have identified a distributed network of neuroanatomical circuits subserving eye-

\footnotetext{
Received Dec. 11, 1995; accepted March 27, 1996

This work was supported in part by the National Institute of Neurological Disorders and Stroke as well as by National Institutes of Health (NIH) Grants ROIAG06796, ROIMH47340, and ROIDA07633 to J.F.D. and NIH Grant 1P50NS26985 to J.D.E.G. The authors thank Peter Herscovitch, Richard Carson, Margaret Daube-Witherspoon, and Paul Baldwin for management and maintenance of the NIH PET facility; Richard Frackowiak and Karl Friston for providing the software for Statistical Parametric Mapping; Jose Maisog for use of software developed for head motion correction; and Ernest Benion for assistance in testing subjects. We also express appreciation to Endel Tulving for helpful comments made on an earlier version of this manuscript.

Correspondence should be addressed to Teresa A. Blaxton, National Institutes of Health, Building 10, Room 5C205, Bethesda, MD 20892.

Copyright $(\mathcal{C} 1996$ Society for Neuroscience $0270-6474 / 96 / 164032-09 \$ 05.00 / 0$
}

blink conditioning (Thompson, 1988). Evidence for involvement of particular brain structures in eyeblink conditioning derives both from lesion studies and from neurophysiological recordings made from single cells within brain structures during conditioning. Lesions in cerebellar dentate-interpositus nuclei eliminate the conditioned eyeblink response, demonstrating that this structure is essential for learning (Glickstein et al., 1983; Clark et al., 1984; McCormick and Thompson, 1984; Yeo et al., 1985a). Additionally, lesions in cerebellar cortex (Yeo et al., 1985b), thalamus (Buchanan and Powell, 1988), basal ganglia (Kao and Powell, 1988), and cingulate gyrus in frontal cortex (Buchanan and Powell, 1982) all can disrupt acquisition and expression of the CR. Hippocampal lesions, however, do not reduce delay conditioning (Schmaltz and Theios, 1972; Berger and Orr, 1983), although neurophysiological recordings after conditioning in rabbits have shown that hippocampal neurons change in a conditioningspecific fashion in the delay paradigm (Berger et al., 1983; Disterhoft et al., 1986).

In agreement with the animal literature, human eyeblink conditioning is impaired in patients with cerebellar lesions (Solomon et al., 1989b; Daum et al., 1993; Topka et al., 1993). Impairments in conditioning also have been reported in normal aging (Solomon et al., 1989a; Carrillo et al., 1993) and Alzheimer's disease (Woodruff-Pak et al., 1990; Solomon et al., 1991). Interestingly, delay conditioning is spared in amnesic patients with hippocampal damage or removal (Daum et al., 1989; Woodruff-Pak, 1993; Gabrieli et al., 1995), confirming that the hippocampus is not necessary for delay conditioning in humans. 


\section{SCAN ORDER $\quad$ CONDITIONING PROCEDURE}

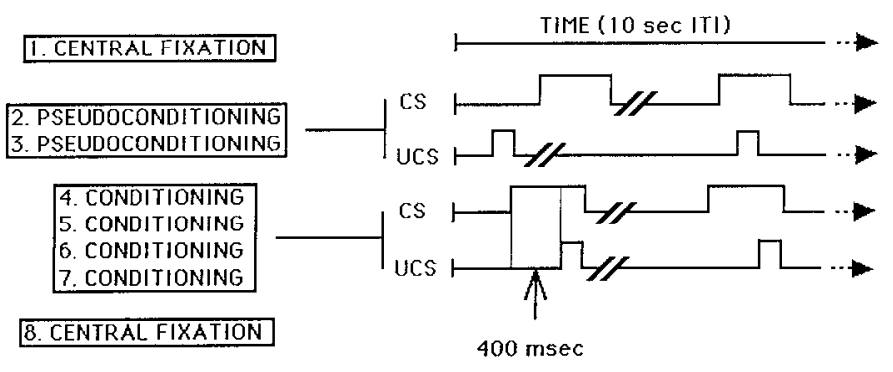

Figure 1. Illustration of experimental paradigm. The order of scans encountered in the study are shown on the left, and stimulus events for pseudoconditioning and conditioning scans are shown on the right. During delay conditioning scans (4-7), $500 \mathrm{msec}$ binaural tones preceded 3-5 psi air puffs to the right eye by $400 \mathrm{msec}$ with an average ITI of $10 \mathrm{sec}$.

The purpose of this study was to investigate $\mathrm{rCBF}$ changes associated with eyeblink conditioning and to determine whether the neuroanatomical structures implicated in previous animal models and human studies are recruited during classical conditioning in normal young humans. $\mathrm{rCBF}$ changes were measured using positron emission tomography (PET) during conditioning, pseudoconditioning, and a fixation control condition. Activation patterns were measured across a series of conditioning scans, allowing the assessment of learning from the very earliest stages and revealing a continuous and cumulative picture of learningrelated changes.

Parts of this paper have been published previously in abstract form (Zeffiro et al., 1993).

\section{MATERIALS AND METHODS}

Subjects. Seven healthy normal voluntcers (one malc, six femalcs; avcrage age, 27 years) served as subjects in the experiment. Each was screened for brain abnormalities via neurological exam and magnetic resonance imaging before being tested. All were strongly right-handed as assessed by the Edinburgh handedness inventory. Informed consent was obtained for participation in the study in keeping with guidelines approved by the Intramural Research Board of the National Institute of Neurological Disorders and Stroke and the Radiation Safety Committee of the National Institutes of Health.

Design. The design of the experiment is shown in Figure 1. The left side of the figure illustrates the sequence of scans in the study, and the right side illustrates conditioning procedures. Three experimental conditions were realized: central fixation rest, in which subjects fixated on a small circle directly in the field of view $(1,8)$; pseudoconditioning, in which presentation of air puffs and tones were uncorrelated with an average 5 sec intertrial interval $(2,3)$; and delay conditioning, in which $500 \mathrm{msec}$ binaural $85 \mathrm{~dB}, 1 \mathrm{kHz}$ tones preceded air puffs by $400 \mathrm{msec}$, with an average $10 \mathrm{sec}$ ITI (4-7). Air puffs were delivered to the right eye at pressures ranging from 3 to 5 psi. Eyelid position was monitored with an infrared detector (Thompson et al., 1994). Stimulus delivery, recording, and scoring of eyeblink responses were controlled by computer (see Akase et al., 1994). Fifteen trials were presented on each conditioning scan, and equal numbers of stimulus events were presented during pseudoconditioning scans.

Scans were arranged in the order depicted in Figure 1 to minimize potential effects of confounding factors that otherwise might obscure interpretation of the results. For example, the baseline resting scans were done at the beginning and end of the PET session to balance out such extraneous effects as dissipation of arousal and increase of subject discomfort across the session. Pseudoconditioning scans were done before conditioning and blocked together. It was necessary for pseudoconditioning to precede conditioning, because any pseudoconditioning scans after conditioning scans might have measured extinction rather than pseudoconditioning processes. The necessary placement of the two pseudoconditioning scans before the conditioning scans was similar to a blocking paradigm (Solomon, 1987) and may have introduced interfer- ence during conditioning, resulting in dissipation of learning. Consequently, the conditioning effects reported are conservative.

PET scanning procedures. Subjects were tested in a Scanditronix PC2048-15B scanner (Milwaukee, WI), which acquires 15 contigunus 6.5 mm slices. During scanning, subjects wore thermoplastic masks to reduce head motion. The field of view of the PET camera was adjusted for individual subjects to ensure imaging of the cerebellum. Each subject received a bolus injection of $37 \mathrm{mC} \mathrm{H}_{2}^{15} \mathrm{O}$ on the eight consecutive scans, and rCBF images were reconstructed using a ramp filter $(6.5 \mathrm{~mm}$ fullwidth half-maximum). Altenuation corrections of innages were made using a reference transmission scan. For all scans, the presentation of stimuli began $\sim 45 \mathrm{sec}$ before the injection and continued for $2.5 \mathrm{~min}$ Imaging began $\sim 15 \mathrm{sec}$ after injection and continued for $1 \mathrm{~min}$ on each scan. After each 2.5 min testing period, stimuli were discontinued until the next scan $\sim 10$ min later.

Analysis of behavioral responses. Examples of eyeblink responses recorded in this study are shown on the left in Figure 2. The top graph shows a CR; the bottom illustrates recordings of the ahsence of an eyeblink elicited by a tone presented alone and an eyeblink response to the air puff presented alone during pseudoconditioning. A response was defined as a CR if it exceeded background baseline activity by at least 4 $\mathrm{SD}$ for 10 successive $1 \mathrm{msec}$ sampling periods, began after the CS onset, and remained above background throughout the CS-US interval before blending into the UR, which was elicited by the air puff. Eyeblinks were defined as alpha responses (and not counted as CRs) if they returned to baseline before US onset and did not blend into the UR. In general, alpha responses were of short latency and duration. To assess learning-related behavioral changes, a one-way ANOVA was performed on scores of proportion of CRs obtained for each subject in the four conditioning blocks.

Analysis of PET findings. PET images were normalized, and head motion correction was performed across the scans using maximum zerocrossover method in which scans 2 through 8 were aligned to scan 1 (Lee et al., 1991; Minoshima et al., 1992). Corrections were made for roll, yaw, and movements between scans. Scans were interpolated from 15 to 43 slice images. Interpolated images were normalized stereotactically to the coordinate system of Talairach and Tournoux (1988) with axial planes parallel to the line connecting the anterior and posterior commissures (AC-PC line). Because the field of view of the PET scanner was 15 contiguous $6.5 \mathrm{~mm}$ axial planes, and the camera had been oriented to include the cerebellum in each subject, the top portion of the brain was not scanned. Regions common to all subjects in the experiment began at an axial plane $40 \mathrm{~mm}$ below the AC-PC line and extended to the plane 24 $\mathrm{mm}$ above this landmark.

A group data analysis was performed for axial planes acquired for all subjects using the Statistical Parametric Mapping technique in which adjustments for global variation in blood flow were made using an ANCOVA procedure (Friston et al., 1991). Pixel-to-pixel planned comparisons then were made between experimental conditions across all axial planes sampled in the study. Collapsing across all subjects, comparisons were made between pseudoconditioning and fixation scans and between conditioning and pseudoconditioning scans. A third weighted contrast was performed comparing rCBF values across the four conditioning scans relative to the pseudoconditioning scans. Values for the conditioning scans were weighted by the behavioral learning measure of mean proportion of CRs produced by the subject group during a given block of conditioning trials $(0.4,0.5,0.5$, and 0.6 , respectively, for the four learning scans). This contrast was similar to a linear regression, but rather than testing for a simple linear trend, instead tested for the specific trend of the learning curve obtained in our subject group. This analysis identified regions in which level of activation (i.e., rCBF changes relative to pseudoconditioning) reflected the acquisition of the CR. For all statistical contrasts, only thosc pixcls diffcring by morc than $3 \mathrm{SD}$ in the planned comparisons $(p<0.001)$ are reported.

\section{RESULTS}

The learning curve for the experiment is presented on the right in Figure 2. The proportion of conditioned eyeblink responses was greater during the conditioning (COND) than pseudoconditioning $(P C)$ scans. The percentage of CRs was greater after the fourth block of conditioning trials $(59 \%)$ than after the first block $(35 \%)$, indicating that substantial associative learning did occur as trials progressed. A one-way ANOVA showed a main effect of block, $F_{(1,6)}=9.49$, mean square error $=0.18, p=0.02$. 

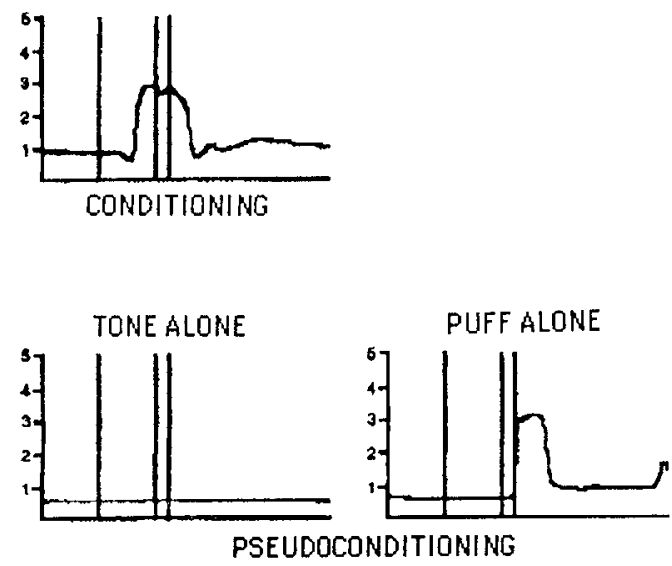

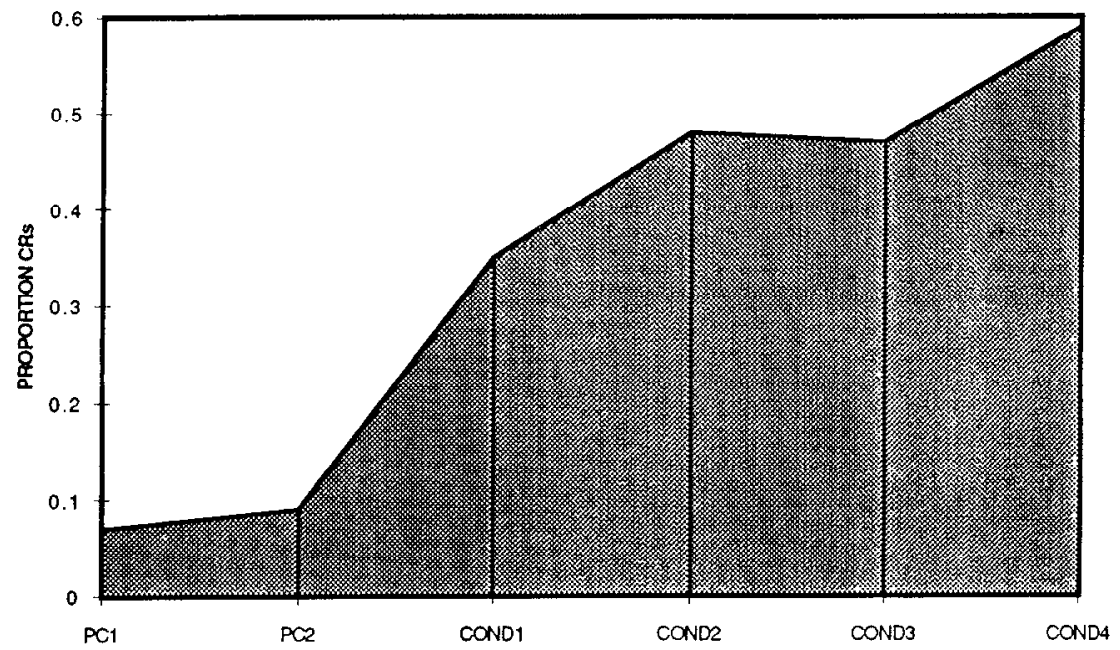

Figure 2. Behavioral data. The top left portion of the figure illustrates a CR recorded during conditioning, whereas the bottom left tracings obtained during pscudoconditioning show the absence of an eyeblink response to the binaural tone (single-line stimulus) and an eyeblink after presentation of the air puff alone (double-line stimulus). The learning curve measured across conditioning trials is presented on the right, showing that the proportion of CRs produced increased over the blocks of trials in the experiment.

Acquisition levels were not as high as we have observed in other protocols in which humans were not tested in the PET scanner (Carrillo et al., 1993; Gabrieli et al., 1995). As already discussed, performance levels likely reflect dissipation of learning produced by interference from the pseudoconditioning scans. The lower conditioning level also could be attributable to a host of other factors associated with the PET scanning environment. These include difficulties in delivering stimuli to subjects positioned in the scanner, distractions from movements of technical personnel within the scanning room, injections of the isotope during ongoing conditioning trials, and the fact that trials were massed as blocks and separated by interscan intervals.

Increases and decreases in rCBF revealed in the planned comparisons of the PET data are presented in Tables 1 and 2, respectively. Regions identified by each of these planned comparisons are listed along with their corresponding Brodmann areas and threedimensional Talairach and Tournoux (1988) coordinates $(x, y, z)$.

Figure 3 provides a pictorial summary of the rCBF changes obtained in the study showing statistical images of change significance derived from planned comparisons for three of the axial levels sampled in the experiment. All planes are parallel to the $\mathrm{AC}-\mathrm{PC}$ line, with one plane sampled from $24 \mathrm{~mm}$ below this landmark, one plane positioned on this line $(0 \mathrm{~mm})$, and one planc $24 \mathrm{~mm}$ above. Activations are shown in red, and deactivations are shown in blue.

The first planned comparison showed that relative to fixation, pseudoconditioning produced activations in left hippocampal formation, bilateral temporal cortex, and basal ganglia $(0 \mathrm{~mm})$ as well as frontal cortex (seen partially at $+24 \mathrm{~mm}$ ). Activations not pictured in Figure 3 also were obtained in inferior right frontal cortex and pons. As may be seen, deactivations (i.e., less activation during pseudoconditioning than during fixation) were observed during pseudoconditioning in left cerebellum and in right temporal cortex $(-24 \mathrm{~mm})$, as well as in other regions listed in Table 2 .

The second row of images in Figure 3 shows that greater activation was observed during conditioning than during pseudoconditioning in right cerebellum $(-24 \mathrm{~mm})$, bilateral frontal cortex (all levels), left thalamus $(0 \mathrm{~mm})$, and left lingual gyrus $(0 \mathrm{~mm})$. Regions activated in axial planes not shown in Figure 1 included right hippocampal formation, pons, and left cerebellum. In terms of learning-related deactivations, blood flow decreased during conditioning as compared with pseudoconditioning scans bilaterally in lateral temporal cortex $(0 \mathrm{~mm})$ as well as right cerebellum $(-24 \mathrm{~mm})$. Deactivation not shown in Figure 3 also was observed in right hippocampal formation.

Results from the weighted contrast are shown in the bottom row of Figure 3. Regions for which changes in activation relative to pseudoconditioning mirrored the rise of the learning curve across conditioning scans included pons $(-24 \mathrm{~mm})$, left caudate, and left hippocampal formation $(0 \mathrm{~mm})$. Additional activated regions not shown in Figure 3 included right temporal cortex, left fusiform gyrus, and left cerebellum. Finally, rCBF decreased in left frontal cortex as learning increased $(+24 \mathrm{~mm})$, revealing a negative coupling between activity in this region and acquisition of the CR.

The nature of learning-related changes in rCBF is illustrated further in Figure 4, in which activation levels for four neuroanatomical regions identified by the weighted analysis are plotted as a function of conditioning scan. The reader will see that activation in right cerebellum $(x, y, z:+16,-34,-20)$, left cerebel$\operatorname{lum}(x, y, z:-28,-54,-32)$, and left hippocampal formation $(x, y, z$ : $-14,-34,0)$ increased across conditioning scans. In contrast, activation in left frontal cortex $(x, y, z:-22,+42,+24)$ systematically decreased as conditioned eyeblink responses increased across scans. This pattern of results suggests that the left frontal cortex may serve a modulatory function, monitoring for systematicity in the environment. When events are unpredictable such as during pseudoconditioning or during early conditioning, this region processes information about salient events. Once acquisition of the CR begins, however, and the environment becomes more predictable, less discovery is necessary and activity in this region declines. The activity of cerebellum, hippocampal formation, and basal ganglia, in contrast, appears to reflect a different kind of processing, possibly concerned with formation of associations among related events such as the CS and US (Cohen and Eichenbaum, 1993).

\section{DISCUSSION}

Our findings of learning-specific activations generally are consistent with results reported previously. For example, there is sub- 
Table 1. Localization of activations from the three statistical comparisons given by Brodmann areas and Talairach and Tournoux (1988) coordinates

\begin{tabular}{|c|c|c|c|c|c|c|}
\hline \multirow[b]{2}{*}{ Activated region } & \multicolumn{2}{|c|}{ Pseudoconditioning vs fixation } & \multicolumn{2}{|c|}{$\begin{array}{l}\text { Conditioning vs } \\
\text { pseudoconditioning }\end{array}$} & \multicolumn{2}{|c|}{ Weighted conditioning } \\
\hline & BA & $(x, y, z)$ & $\mathrm{BA}$ & $(x, y, z)$ & $\mathrm{BA}$ & $(x, y, z)$ \\
\hline \multirow[t]{3}{*}{ Left frontal lobe } & 10 & $(-16,+50,+20)$ & 10 & $(-18,+36,+24)$ & & \\
\hline & 10 & $(-34,+44,+20)$ & 10 & $(-24,+58,0)$ & & \\
\hline & 11 & $(-32,+38,-16)$ & 11 & $(-24,+28,-24)$ & & \\
\hline \multirow[t]{7}{*}{ Right frontal lobe } & 11 & $(+32,+28,-16)$ & 10 & $(+32,+54,0)$ & & \\
\hline & & & 10 & $(+24,+58,+4)$ & & \\
\hline & & & 10 & $(+14,+60,-4)$ & & \\
\hline & & & 11 & $(+12,+54,-16)$ & & \\
\hline & & & 11 & $(+8,+42,-12)$ & & \\
\hline & & & $44 / 45$ & $(+44,+20,+8)$ & & \\
\hline & & & 47 & $(+32,+20,-16)$ & & \\
\hline Antcrior cingulatc & & & $24 / 32$ & $(|6| 34,, \mid 4)$ & & \\
\hline \multirow[t]{4}{*}{ Left temporal lobe } & 21 & $(-48,-22,0)$ & & & & \\
\hline & 21 & $(-48,-6,-4)$ & & & & \\
\hline & 21 & $(-48,-16,-12)$ & & & & \\
\hline & 39 & $(-46,-60,+16)$ & & & & \\
\hline Right temporal lobe & $20 / 38$ & $(+28,-2,-36)$ & & & $22 / 38$ & $(+46,+12,-4)$ \\
\hline Right putamen & - & $(+14,12,0)$ & & & & \\
\hline Left caudate & & & & & - & $\begin{array}{l}(-6,+8,-4) \\
(-4,+2,+4)\end{array}$ \\
\hline Right caudate & - & $(+2,+6,8)$ & & & & \\
\hline Left thalamus & & & - & $\begin{array}{l}(-4,+4,+4) \\
(-10,-14,+4)\end{array}$ & & \\
\hline \multicolumn{7}{|l|}{ Left hippocampal } \\
\hline formation & $30 / 35$ & $(-24,-34,+4)$ & & & $\begin{array}{l}27 / 30 \\
30 / 35\end{array}$ & $\begin{array}{l}(-14,-34,0) \\
(-24,-36,+4)\end{array}$ \\
\hline \multicolumn{6}{|l|}{ Right hippocampal } & \\
\hline Left fusiform gyrus & & & & & $\begin{array}{l}37 \\
18\end{array}$ & $\begin{array}{l}(-32,-38,-12) \\
(-22,-94,-12)\end{array}$ \\
\hline Left lingual gyrus & & & $\begin{array}{l}18 \\
18\end{array}$ & $\begin{array}{l}(-12,-76,0) \\
(-2,-68,0)\end{array}$ & & \\
\hline Pons & - & $\begin{array}{l}(-6,-10,-20) \\
(-2,-22,-20)\end{array}$ & - & $(+14,-22,-12)$ & - & $(+2,-38,-28)$ \\
\hline Left cerebellum & & & - & $\begin{array}{l}(-28,-38,-40) \\
(-16,-40,-20)\end{array}$ & - & $\begin{array}{l}(-28,-54,-32) \\
(-30,-76,-40)\end{array}$ \\
\hline Right cerebellum & & & - & $\begin{array}{l}(+16,-34,-20) \\
(+18,-60,-24) \\
(+30,-58,-20)\end{array}$ & & \\
\hline
\end{tabular}

Regions are listed in anterior to posterior order. $B A$ indicates Brodmann areas. All results are significant at $p<0.001$.

stantial precedent for the observation of bilateral changes in cerebellum. Bilateral cerebellar increases in glucose metabolism have been observed in human subjects after eyeblink conditioning (Logan and Grafton, 1995). Rabbits show bilateral behavioral responses when the air puff US is presented to one eye, although responses in the unreinforced eye are smaller (Disterhoft et al., 1977). Furthermore, although unilateral lesions of cerebellar cortex or deep nuclei impair conditioning, considerable transfer of training nevertheless occurs when rabbits are then trained on the unlesioned and previously naive side (McCormick et al., 1982; Yeo et al., 1985b; Lavond et al., 1994). The bilaterality of this transfer of training effect within the cerebellum probably arises from extensive crossing of the auditory pathway, which permits bilateral projection of the tone via mossy fibers from the dorsolateral pontine nuclei (Yeo et al., 1985c) or directly as mossy fibers from the trigeminal complex (Van Ham and Yeo, 1992). Finally, after classical eyeblink conditioning, neuroanatomical changes occur bilaterally in Purkinje cell dendrites (Anderson, 1993), conditioning-specific immunoreactivity for gamma PKC increases bilaterally in cerebellar lobule HVI (Van der Zee et al., 1995), and multiple neuron responses correlated temporally with behavioral CRs are observed in bilateral cerebellum (Polchenar and Patterson, 1985; Polchenar et al., 1986).

In other regions, lesions of the frontal cortex (Eichenbaum et al., 1974; Buchanan and Powell, 1982), thalamus (Buchanan and Powell, 1988; Woody et al., 1991), and basal ganglia (Kao and Powell, 1988) have been reported to impair the eyeblink response in rabbits. Electrophysiological studies in animals have shown firing patterns in the hippocampal formation that correlate with 
Table 2. Localization of deactivations from the three statistical comparisons given by Brodmann areas and Talairach and Tournoux (1988) coordinates

\begin{tabular}{|c|c|c|c|c|c|c|}
\hline \multirow[b]{2}{*}{ Deactivated region } & \multicolumn{2}{|c|}{ Pseudoconditioning vs fixation } & \multicolumn{2}{|c|}{$\begin{array}{l}\text { Conditioning vs } \\
\text { pseudoconditioning }\end{array}$} & \multicolumn{2}{|c|}{ Weighted conditioning } \\
\hline & $\mathrm{BA}$ & $(x, y, z)$ & $\mathrm{BA}$ & $(x, y, z)$ & $\mathrm{BA}$ & $(x, y, z)$ \\
\hline \multirow[t]{4}{*}{ Left frontal lobe } & & & & & 10 & $(-22,+42,+24)$ \\
\hline & & & & & 10 & $(-6,+48,-8)$ \\
\hline & & & & & 11 & $(-28,+38,-8)$ \\
\hline & & & & & 11 & $(-28,+32,-12)$ \\
\hline Right frontal lobe & 10 & $(+8,+44,-8)$ & & & & \\
\hline Anterior cingulate & 32 & $(-14,+22,-8)$ & & & & \\
\hline \multirow[t]{3}{*}{ Left temporal lobe } & 37 & $(-50,-60,0)$ & 21 & $(-48,-20,0)$ & & \\
\hline & & & 22 & $(-46,-4-4)$ & & \\
\hline & & & 37 & $(-50,-66,+4)$ & & \\
\hline \multirow[t]{3}{*}{ Right temporal lobe } & 21 & $(+42,-10,-24)$ & 21 & $(+38,-2,-16)$ & & \\
\hline & & & 37 & $(+52,-64, \mid 8)$ & & \\
\hline & & & 38 & $(+20,+10,-32)$ & & \\
\hline Right putamen & & & - & $(+36,-16,-8)$ & & \\
\hline Left thalamus & - & $(-8,-14,+4)$ & & & & \\
\hline Right thalamus & - & $(+12,-18,0)$ & & & & \\
\hline \multicolumn{7}{|l|}{ Right hippocampal } \\
\hline formation & 35 & $(+34,-14,-24)$ & 27 & $(+40,-32,-4)$ & & \\
\hline \multirow[t]{2}{*}{ Left fusiform gyrus } & 37 & $(-38,-48,-16)$ & & & & \\
\hline & 37 & $(-52,-62,-16)$ & & & & \\
\hline Right lingual gyrus & 18 & $(+16,-96,-4)$ & & & & \\
\hline Pons & - & $(+12,-20,-16)$ & & & & \\
\hline Left cerebellum & - & $(-36,-70,-12)$ & & & & \\
\hline & & $(-4,-72,-36)$ & & & & \\
\hline & & $(-34,-48,-24)$ & & & & \\
\hline Right cerebellum & - & $(+16,-34,-20)$ & - & $(+44,-66,-24)$ & & \\
\hline & & $(+24,-74,-12)$ & & & & \\
\hline
\end{tabular}

Regions are listed in anterior to posterior order. BA indicates Brodmann areas. All results are significant at $p<0.001$.

the development of behavioral CRs (Berger et al., 1983; Disterhoft et al., 1986). Further, glucose metabolism is elevated in ipsilateral hippocampus after conditioning in humans (Logan and Grafton, 1995). We observed learning-specific activation in all of these regions as well as in right temporal cortex and left fusiform and lingual gyri, which have not been studied previously in this task in animals.

Modulation of neurological structures during conditioning also was evidenced by learning-specific deactivations in left frontal lobe, bilateral temporal cortex, and right hemisphere structures including putamen, hippocampal formation, and cerebellum. In the only other published report in which O-15 PET was used to study eyeblink conditioning, deactivations also were observed in right putamen and cerebellum (Molchan et al., 1994). Indeed these deactivations, which reveal less activation on memory tasks than on control tasks, have become a hallmark of learning and memory paradigms in neuroimaging studies (Squire et al., 1992; Raichle et al., 1994; Blaxton et al., in press; Gabrieli et al., in press). Deactivations reflect the savings enjoyed by brain regions during processing of repeated stimuli that have been presented and processed before. This interpretation is supported by singlecell recordings from temporal cortex in nonhuman primates showing decreases in individual cell responses to target stimuli as those stimuli are repeated during an experimental session (Miller et al., 1991).

It is interesting to note that although brain regions generally were modified in terms of either activation of deactivation, there were two regions that showed both types of learning-specific changes. The medial aspect of right hippocampal formation was activated during learning, whereas the lateral aspect was deactivated relative to pseudoconditioning. Similarly, medial right cerebellum was activated, whereas lateral right cerebellar cortex was deactivated during learning. Although this question merits additional investigation, these results may reflect the operation of different learning mechanisms.

\section{Statistical methods}

The involvement of brain regions in eyeblink conditioning was examined in two ways in this study: a subtractive approach, in which relative blood flow during conditioning trials was compared statistically with that observed during pseudoconditioning trials, and a correlative approach, in which the blood flow during conditioning trials was weighted relative to the total amount of behavioral acquisition. As can been seen in Tables 1 and 2, the brain regions that showed highly significant $\mathrm{rCBF}$ changes in the two analyses were not identical, although there was overlap. Significant changes were detected in some important regions, including left frontal lobe, right temporal lobe, pons, and the left cerebellum, with both analyses. Some regions including right frontal lobe, anterior cingulate, left temporal lobe, right hippocampal formation, left lingual gyrus, and right cerebellum only showed changes with the subtractive technique. Other regions including left caudate, left hippocampal formation, and left fusi- 


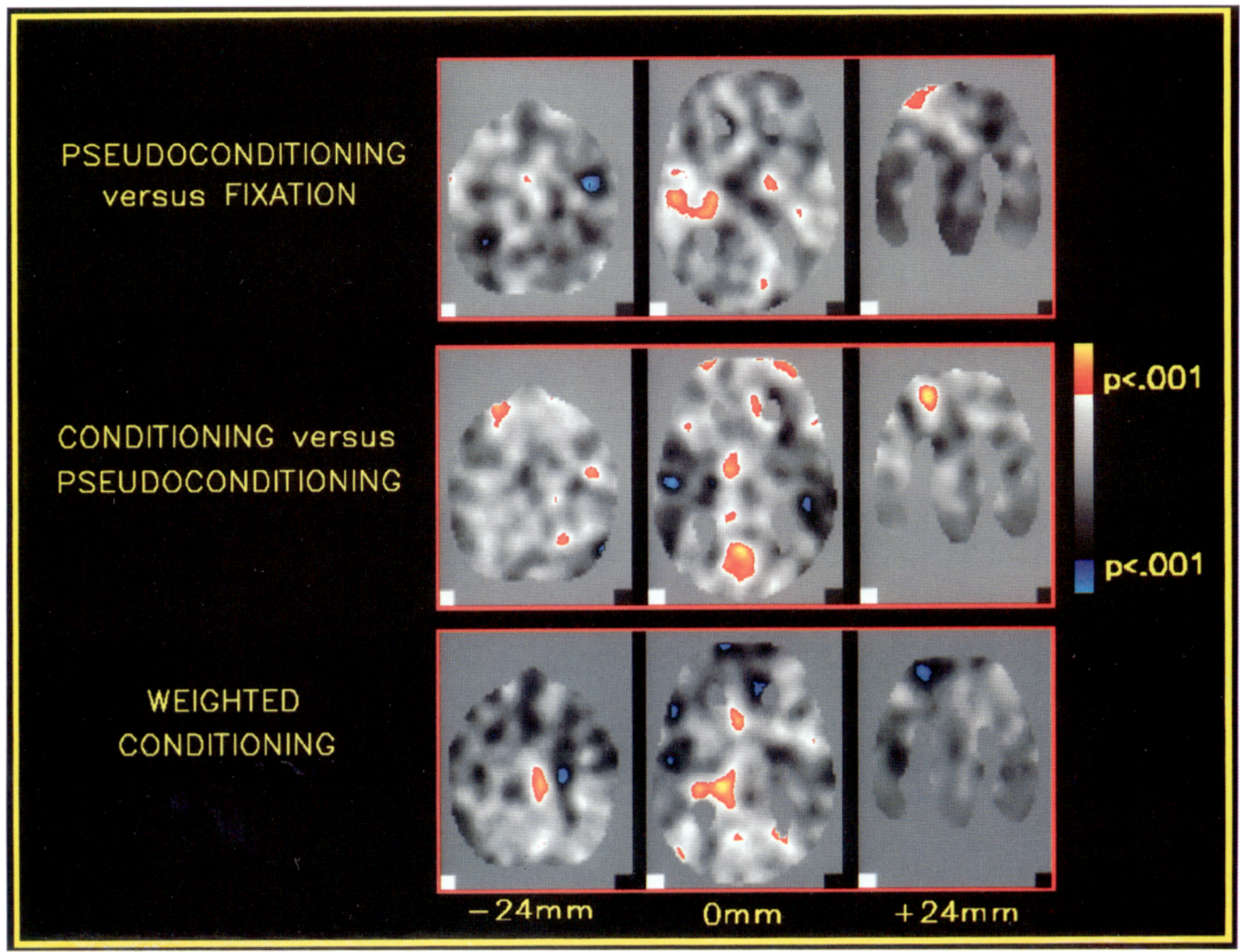

Figure 3. Images of change significance for the three planned comparisons at three different axial levels (low, midline, and high) sampled in the experiment. Activations are shown in red and deactivations in blue. The left column shows a plane sampled from $24 \mathrm{~mm}$ below the AC-PC line, the middle column shows results from the plane positioned on this line $(0 \mathrm{~mm})$, and the right column shows images obtained from a plane $24 \mathrm{~mm}$ above this line.

form gyrus only showed learning-specific changes with the weighted measure.

Both approaches to evaluating the involvement of brain regions during the conditioning process are defensible and illuminating. Additional study may demonstrate that those regions showing changes with both analyses may be more engaged or critical for acquisition. The weighting or correlative procedure seems especially powerful because of its sensitivity to the dynamics of the learning process. Our current knowledge of the sequence by which human brain regions become involved during learning is too fragmentary at present, however, to allow us to choose which of the approaches yields the definitive pattern of results.

\section{rCBF changes during learning}

Some of the brain regions involved in learning in the present study also have been implicated in other PET experiments examining procedural learning and memory with human subjects. For example, right cerebellar activation has been associated with learning sequential motor movements (Friston et al., 1992) and pursuit rotor tasks (Grafton et al., 1993). Jenkins et al. (1994) reported rCBF increases in bilateral cerebellum and left thalamus and decreases in right hippocampus and left temporal cortex (area 37) as subjects either performed previously learned or new motor sequences. Additionally, Grafton et al. (1993) found rCBF increases for pursuit rotor learning in right temporal cortex.

Verbal learning paradigms studied with PET also have implicated regions close to those identified in our eyeblink conditioning study. For example, rCBF increases in frontal cortex have been observed during verb generation (Petersen et al., 1988, 1989; Wise et al., 1991; Pardo and Fox, 1993), learning related word pairs (Shallice et al., 1994), and lexical decision (Frith et al., 1991). Right frontal regions have been activated in a variety of verbal memory paradigms as well, including auditory sentence recognition (Tulving et al., 1994), primed word stem completion (Squire et al., 1992), and face recognition (Haxby et al., 1993). Tests of cued recall, word association, and category member generation have been reported to engage left hippocampal formation (Frith et al., 1991; Blaxton et al., in press), whereas tasks such as word stem completion and auditory sentence recognition have produced activation of right hippocampus (Squire et al., 1992; Tulving et al., 1994). 


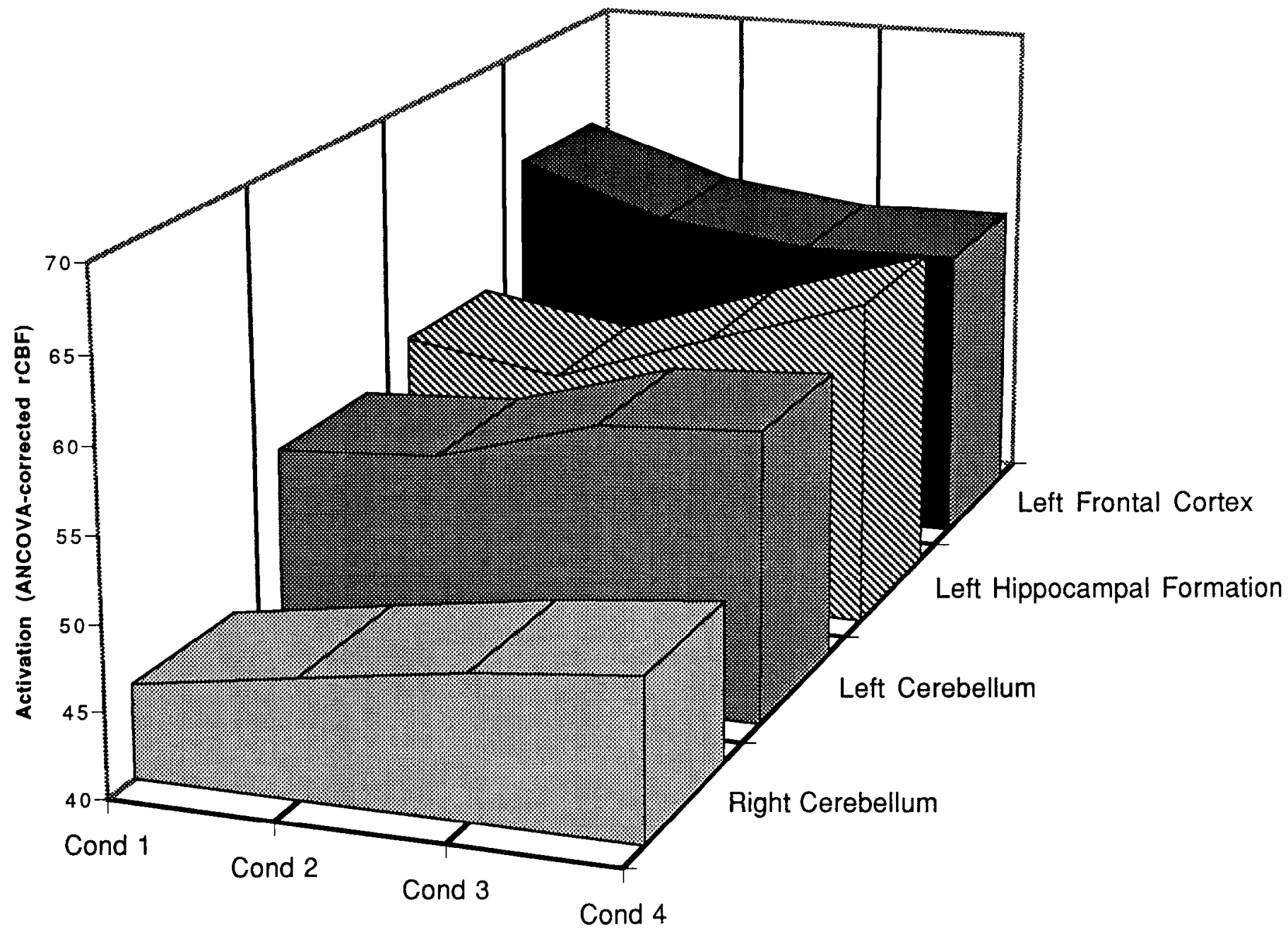

Figure 4. Changes in activation across conditioning trials for regions in left frontal cortex, left hippocampal formation, and cerebellum. Activation in cerebellum and left hippocampal formation increased as learning trials progressed, but the left frontal cortcx showed the opposite trend, actually becoming less activated as the CS-US association was learned.

\section{Substrates of learning}

The findings observed in the present experiment as well as those reported elsewhere in learning paradigms reflect the operation of a distributed network of structures that change during the acquisition of even a relatively simple associative task. The modulations in $\mathrm{rCBF}$ that we observed in cerebellum, thalamus, caudate, and frontal cortex all follow previous findings from lcsion experiments in animals, demonstrating that each of these neuroanatomical regions may be engaged during eyeblink conditioning. Modulations of hippocampal activity are consistent with neurophysiological evidence in animals showing that hippocampal neurons are responsive in delay conditioning, but must be interpreted differently because of evidence from animals (Schmaltz and Theios, 1972) and humans (Gabrieli et al., 1995) that hippocampal lesions do not aflect acquisition of delay conditioning. It is possible that whereas activation in the hippocampus and other structures is not necessary for conditioning in this paradigm, these structures are, nevertheless, engaged in processing that would facilitate more complex forms of learning. For example, hippocampal lesions can disrupt more cognitively demanding forms of conditioning such as trace conditioning, conditioned inhibition, latent inhibition, and blocking that require coding of temporal relations or suppression of irrelevant stimuli (Salafia, 1982; Solomon, 1987; Moyer et al., 1990). Thus, the hippocampus may participate in the creation of associations that do not mediate delay conditioning per se, but that mediate the expression of other forms of knowledge derived from the learned associations. This feature of hippocampal function has been described by memory theorists (Cohen and Eichenbaum, 1993) and may be a principle that applies to other brain regions as well.

Distinctions among forms of learning have been studied widely in animals and humans, and there is considerable evidence for a distinction between two forms of associative learning that are subserved by separate sets of neural structures. Similar to conditioning, learning of simple habits (Mishkin et al., 1984) or procedures (Cohen and Squire, 1980; Gabrieli et al., 1993) is mediated by cerebellar and striatal structures. In contrast, representational (Mishkin et al., 1984) or declarative (Cohen and Squire, 1980) learning is thought to depend on the hippocampal formation and related structures. The patterns of results in this PET study demonstrate that the acquisition of an association as straightforward as that between a tone and an air puff recruits multiple neural circuits subserving several forms of learning, only a subset of which may be necessary to mediate acquisition of a particular procedural CR. 


\section{REFERENCES}

Akase E, Thompson LT, Disterhoft JF (1994) A system for quantitative analysis of associative learning. 2. Real-time software for MS-DOS microcomputers. J Neurosci Methods 54:119-130.

Anderson BJ (1993) The effects of paired and unpaired eyeblink conditioning on Purkinje cell morphology. $\mathrm{PhD}$ thesis, University of Illinois at Urbana Champaign

Berger TW, Orr WB (1983) Hippocampectomy selectively disrupts discrimination reversal conditioning of the rabbit nictitating membrane response. Behav Brain Res 8:49-68.

Berger TW, Rinaldi PC, Weisz DJ, Thompson RF (1983) Single-unit analysis of different hippocampal cell types during classical conditioning of rabbit nictitating membrane response. J Neurophysiol 50:1197-1219.

Blaxton TA, Bookheimer SY, Zeffiro TA, Figlozzi CM, Gaillard WD, Theodore WH (1996) Functional mapping of human memory using PET: comparisons of conceptual and perceptual tasks. Can J Exp Psychol, in press.

Buchanan SL, Powell DA (1982) Cingulate cortex: its role in Pavlovian conditioning. J Comp Physiol Psychol 96:755-774.

Buchanan SL, Powell DA (1988) Parasagittal thalamic knife cuts retard Pavlovian eyeblink conditioning and abolish the tachycardiac component of the heart rate conditioned response. Brain Res Bull 21:723-729.

Carrillo MC, Thompson LT, Naughton BJ, Gabrieli JDE, Disterhoft JF (1993) Aging impairs trace eyeblink conditioning in humans independent of changes in the unconditioned response. Soc Neurosci Abstr 19:386.

Clark GA, McCormick DA, Lavond DG, Thompson RF (1984) Effects of lesions of cerebellar nuclei on conditioned behavioral and hippocampal neuronal responses. Brain Res 291:125-136.

Cohen NJ, Eichenbaum H (1993) Memory, amnesia, and the hippocampal system. Cambridge: MIT.

Cohen NJ, Squire LR (1980) Preserved learning and retention of pattern-analyzing skill in amnesia: dissociation of "knowing how" and "knowing that." Science 210:207-209.

Daum I, Channon S, Canavan AGM (1989) Classical conditioning in patients with severe memory problems. J Neurol Neurosurg Psychiatry $52: 47-51$

Daum I, Schugens MM, Ackerman H, Lutzenberger W, Dichgans J, Birbaumer N (1993) Classical conditioning after cerebellar lesions in humans. Behav Neurosci 107:748-756.

Disterhoft JF, Kwan HH, Lo WD (1977) Nictitating membrane conditioning to tone in the immobilized albino rabbit. Brain Res 137:127-143.

Disterhoft JF, Coulter DA, Alkon DL (1986) Conditioning-specific membrane changes of rabbit hippocampal neurons measured in vitro. Proc Natl Acad Sci USA 83:2733-2737.

Eichenbaum H, Potter H, Papsdorf J, Butter CM (1974) Effects of frontal cortex lesions on differentiation and extinction of the classically conditioned nictitating membrane response in rabbits. J Comp Physiol Psychol 86:179-186.

Friston KJ, Frith CD, Liddle PF, Frackowiak RSJ (1991) Comparing functional (PET) images: the assessment of significant change. J Cereb Blood Flow Metab 11:690-699.

Friston KJ, Frith CD, Passingham RE, Liddle PF, Frackowiak RSJ (1992) Motor practice and neurophysiological adaptation in the cerebellum: a positron tomography study. Proc R Soc Lond [Biol] 248:223-228.

Frith CD, Friston K, Liddle PF, Frackowiak RSJ (1991) A PET study of word finding. Neuropsychologia 29:1137-1148.

Gabrieli JDE, Corkin S, Mickel SF, Growdon JH (1993) Intact acquisition and long-term retention of mirror-tracing skill in Alzheimer's disease and in global amnesia. Behav Neurosci 107:899-910.

Gabrieli JDE, McGlinchey-Berroth R, Carrillo MC, Gluck M, Cermak LS, Disterhoft JF (1995) Intact delay-eyeblink classical conditioning in amnesia. Behav Neurosci 109:819-827.

Gabrieli JDE, Desmond JE, Demb JB, Wagner AD, Stone MV, Vaidya CJ, Glover GH (1996) Functional magnetic resonance imaging of semantic memory processes in the frontal lobes. Psychol Sci, in press.

Glickstein M, Hardiman MJ, Yeo CH (1983) The effects of cerebellar lesions on the conditioned nictitating nembrane response of the rabbit. J Physiol (Lond) 341:30-31.

Gormezano I (1966) Classical conditioning. In: Experimental methods and instrumentation in psychology (Sidowski JB, ed), pp 385-420. New York: McGraw-Hill.

Grafton ST, Tyszka M, Colletti PM (1993) Longitudinal changes of regional cerebral blood flow during procedural motor learning in humans. J Cereb Blood Flow Metab 1[Suppl 13]:S497.
Haxby JV, Horwitz B, Maisog JM, Ungerleider LG, Mishkin M, Schapiro MB, Rapoport SI, Grady CL (1993) Frontal and temporal participation in long-term recognition memory for faces: a PET-rCBF activation study. J Cereb Blood Flow Metab 13[Suppl 1]:S499.

Jenkins IH, Brooks DJ, Nixon PD, Frackowiak RSJ, Passingham RE (1994) Motor sequence learning: a study with positron emission tomography. J Neurosci 14:3775-3790.

Kao KT, Powell DA (1988) Lesions of the substantia nigra retard Pavlovian eye-blink but not heart rate conditioning in the rabbit. Behay Neurosci 102:515-525.

Lavond DG, Kanzawa SA, Ivkovich D, Clark RE (1994) Transfer of learning but not memory after unilateral cerebellar lesion in rabbits. Behav Neurosci 108:284-293.

Lee KS, Berger KL, Mintun MA (1991) Mathematical registration of PET images enhances detection of neural activation by subtraction image analysis. J Cereb Blood Flow Metab 11[Suppl 2]:S557.

Logan CG, Grafton ST (1995) Functional anatomy of human eyeblink conditioning determined with regional cerebral glucose metabolism and positron emission tomography. Proc Natl Acad Sci USA 92:7500-7504.

McCormick DA, Thompson RF (1984) Cerebellum: essential involvement in the classically conditioned eyelid response. Science 223:296-299.

McCormick DA, Clark GA, Lavond DG, Thompson RF (1982) Initial localization of the memory trace for a basic form of learning. Proc Natl Acad Sci USA 79:2731-2735.

Miller EK, Li L, Desimone R (1991) A neural mechanism for working and recognition memory in inferior temporal cortex. Science 254:1377-1379.

Minoshima S, Berger KL, Lee KS, Mintun MA (1992) An automated method for rotational correction and centering of three-dimensional functional brain images. J Nucl Med 33:1579-1585.

Mishkin M, Malamut B, Bachevalier J (1984) Memories and habits: two neural systems. In: Neurobiology of learning and memory (Lynch G, McGaugh JL, Weinberger NM, eds), pp 65-77. New York: Guilford.

Molchan SE, Sunderland T, McIntosh AR, Herscovitch P, Schreurs BG (1994) A functional anatomical study of associative learning in humans. Proc Natl Acad Sci USA 91:8122-8126.

Moyer JRJ, Deyo RA, Disterhoft JF (1990) Hippocampal lesions impair trace eye-blink conditioning in rabbits. Behav Neurosci 104:243-252.

Pardo JV, Fox P'I (1993) Preoperative assessment of the cerebral hemispheric dominance for language with CBF PET. Hum Brain Mapp 1:57-68.

Petersen SE, Fox PT, Posner MI, Mintun M, Raichle ME (1988) Positron emission tomographic studies of the cortical anatomy of singleword processing. Nature 331:585-589.

Petersen SE, Fox PT, Posner MI, Mintun M, Raichle ME (1989) Positron emission tomographic studies of the processing of single words. J Cognit Neurosci 1:153-170.

Polchenar BE, Patterson MM (1985) Cerebellar control of the conditioned nictitating membrane response in rabbit: bilateral neural plasticity. Soc Neurosci Abstr 11:1041.

Polchenar BE, Aluko U, Donahue S, Patterson MM (1986) Bilateral neural plasticity in the cerebellum during classical conditioning of the nictitating membrane response in rabbit. Soc Neurosci Abstr 12:181.

Raichle ME, Fiez JA, Videen TO, MacLeod AK, Pardo JV, Fox PT, Petersen SE (1994) Practice-related changes in human brain functional anatomy during nonmotor learning. Cereb Cortex 4:8-26.

Salafia WR (1982) Pavlovian conditioning, information processing, and the hippocampus. In: Classical conditioning, 3rd Ed (Gormezano I, Prokasy WF, Thompson RF, eds), pp 197-216. Hillsdale, NJ: Lawrence Erlbaum.

Schmaltz LW, Theios J (1972) Acquisition and extinction of a classically conditioned response in hippocampectomized rabbits (Oryctolagus $\mathrm{cu}$ niculus). J Comp Physiol Psychol 79:328-333.

Shallice T, Fletcher P, Frith CD, Grasby P, Frackowiak RSJ, Dolan RJ (1994) Brain regions associated with acquisition and retrieval of verbal episodic memory. Nature 368:633-635

Solomon PR (1987) Neural and behavioral mechanisms in blocking and latent inhibition. In: Classical conditioning, 3rd Ed (Gormezano I, Prokasy WF, Thompson RF, eds), pp 117-159. Hillsdale, NJ: Lawrence Erlbaum.

Solomon PR, Pomerleau D, Bennett L, James J, Morse DL (1989a) Acquisition of the classically conditioned eyeblink response in humans over the life span. Psychol Aging 4:34-41. 
Solomon PR, Stowe GT, Pendlebury WW (1989b) Disrupted eyelid conditioning in a patient with damage to cerebellar afferents. Behav Neurosci 103:898-902.

Solomon PR, Levine E, Bein T, Pendlebury WW (1991) Disruption of classical conditioning in patients with Alzheimer's disease. Neurobiol Aging 12:283-287.

Squire LR, Ojemann JG, Miezin FM, Petersen SE, Videen TO, Raichle ME (1992) Activation of the hippocampus in normal humans: a functional anatomical study of memory. Proc Natl Acad Sci USA 89:1837-1841.

Talairach J, Tournoux P (1988) Co-planar stereotaxic atlas of the human brain, 3-dimensional proportional system: an approach to cerebral imaging. New York: Georg Thieme Verlag.

Thompson LT, Moyer JR, Akase E, Disterhoft JF (1994) A system for quantitative analysis of associative learning. 1. I Iardware interfaces with cross-species applications. J Neurosci Methods 54:109-117.

Thompson RF (1988) A model system approach to memory. In: Memory: interdisciplinary approaches (Solomon PR, Goethals JB, Kelley CM, Stephens BR, eds). New York: Springer.

Topka H, Valls-Sole J, Massaquoi SG, Hallett M (1993) Deficit in classical conditioning in patients with cerebellar degeneration. Brain 116:961-969.

Tulving E, Kapur S, Markowitsch HJ, Craik FIM, Habib R, Houle S (1994) Neuroanatomical correlates of retrieval in episodic memory: auditory sentence recognition. Proc Nati Acad Sci USA 91: 2012-2015.

Van der Zee EA, Palm IF, Kronforst MA, Maizels ET, Shanmugam M, Hunzicker-Dunn M, Disterhoft JF (1995) Trace and delay eyeblink conditioning induce alterations in the immunoreactivity for $\mathrm{PKCg}$ in the rabbit hippocampus. Soc Neurosci Abstr 21:1218.
Van Ham JJ, Yeo CH (1992) Somatosensory trigeminal projections to the inferior olive, cerebellum, and other precerebellar nuclei in rabbits. Eur J Neurosci 4:302-317.

Wise R, Chollet F, Hadar U, Friston K, Hoffner E, Frackowiak R (1991) Distribution of cortical neural networks involved in word comprehension and word retrieval. Brain 114:1803-1817.

Woodruff-Pak DS (1993) Eyeblink classical conditioning in H.M.: delay and trace paradigms. Behav Neurosci 107:911-925.

Woodruff-Pak DS, Finkbiner RG, Sasse DK (1990) Eyeblink conditioning discriminates Alzheimer's patients from non-demented aged. NeuroReport 1:45-49.

Woody CD, Gruen E, Melamed O, Chizhevsky V (1991) Patterns of unit activity in the rostral thalamus of cats related to short-latency discrimination between different auditory stimuli. J Neurosci 11:48-58.

Yeo CH, Hardiman MJ, Glickstein M (1985a) Classical conditioning of the nictitating membrane response of the rabbit. I. Lesions of the cerebellar nuclei. Exp Brain Res 60:87-98.

Yeo CH, Hardiman MJ, Glickstein M (1985b) Classical conditioning of the nictitating membrane response of the rabbit. II. Lesions of the cerebellar cortex. Exp Brain Res 60:99-113.

Yeo CH, Hardiman MJ, Glickstein M (1985c) Classical conditioning of the nictitating membrane response of the rabbit. III. Connections of cerebellar lobule HVI. Exp Brain Res 60:114-126.

7effiro TA, Blaxton TA, Gahrieli IDF, Bookheimer SY, Carrillo MC, Benion E, Disterhoft JF, Theodore WH (1993) Regional cerebral blood flow changes during eyeblink conditioning in man. Soc Neurosci Abstr 19:1078. 